\title{
Everyday life in the face of conflict: Sumud as a spatial quotidian practice in Palestine
}

\author{
Jan Busse ${ }^{1}$ \\ Published online: 15 February 2022 \\ (c) Springer Nature Limited 2022
}

\begin{abstract}
By drawing from the engagement with the empirical case of sumud (Arabic: steadfastness) in Palestine, this article focuses on the social and political implications of everyday life in conflict settings. Proposing an alternative perspective on conflicts, this article argues that it is important also to focus on normalcy of everyday life in conflict settings and how this transforms conflict dynamics. Hence, contrary to the assumption that there is an opposition between the normalcy of everyday life and violent conflicts, this article argues that everyday life is not disrupted but that it goes on also in the face of conflicts, it only has to adapt to it. Building on Stephen Lubkemann's concept of 'culturally scripted life projects', this article will show how the attempt to pursue a regular life unfolds in an everyday setting in order to escape the predominant conflict/resistance frame. In addition to sumud as an individual practice this article highlights the broader social and political role this concept assumes in the context of Palestinian nationalism. In order to illustrate this argument, this article presents sumud as a spatial quotidian practice which is primarily aimed at realising culturally scripted life project in the face of the Israeli occupation.
\end{abstract}

Keywords Culturally scripted life projects · Everyday life · Everyday normalcy · Palestine $\cdot$ Resistance $\cdot$ Sumud

\section{Introduction}

Violent conflicts are often studied in relation to a state of emergency and as a more or less severe suspension of normal life. Hence, conflicts appear as the very opposite of normalcy. Against this background, it is no surprise that conflicts tend to have a considerable effect on what can be termed as their social environments, often colonising all social relations that come close to a given conflict - including many scholarly analyses. As the case of Palestine amply illustrates, almost everything that

Jan Busse

jan.busse@unibw.de

1 Institute of Political Science, University of the Bundeswehr Munich, Neubiberg, Germany 
occurs in Palestine and Palestinian social life tends to be primarily observed through the lens of the conflict. For instance, Palestinians are often portrayed as victims of the occupation, as heroic fighters against oppression, or as terrorists. As a result, there is a focus on the predominance of the Israeli occupation, on stark arguments in favour of it, or fierce resistance against it (for a critique see Busse 2018: 5).

Instead of focusing on how conflicts - such as the Israeli-Palestinian one - play out, this article is interested in the normalcy of everyday life in conflict settings and the factors that underpin normalcy of everyday life in that context. It also studies broader political and social currents underpinning an ongoing conflict, in this specific but also in many other cases, in particular nationalism. On that basis, this contribution argues that conflicts do not suspend normalcy; rather, they lead to a reconfiguration of everyday normalcy to which more attention needs to be directed. This article studies this question both conceptually and empirically by turning to the Palestinian concept of sumud (steadfastness), and it highlights that there are 'reinforcing' frames that try to insulate the everyday from conflicts. With a view to this latter dimension, this insulation of everyday life feeds back into the conflict by providing alternative political framings that transform political identities. Herein lies the political/social function of everyday life in conflict settings. Sumud is not a negligible fact of Palestinian social life, but a concept widely established in Palestinian national discourse, which allows moving amorphous everyday practices into a concrete and societally clearly labelled concept navigating between fragile individual normalcy and social/political purpose. In this sense, sumud is unquestionably political, as it only make sense as a response to the Israeli occupation. Sumud thereby serves as a means to constitute an encompassing Palestinian national identity, which cannot be disrupted by the occupation.

In order to stress that an exclusive focus on conflicts often occludes more comprehensive social dynamics, I will use the term 'conflict/resistance frame' as a conceptual tool which shows that certain observations are pre-structured by assumptions naturally associated with conflicts. ${ }^{1}$ Strikingly, this conflict/resistance frame affects both scholars doing research on conflict settings as well as individuals who are affected by conflicts. In both cases, we can observe a certain over-emphasis on the pervasiveness of the conflict in shaping all aspects of everyday life. ${ }^{2}$

Building on Stephen Lubkemann's concept of 'culturally scripted life projects' (Lubkemann 2008: 14), briefly defined here as the striving for everyday normalcy

\footnotetext{
1 In IR, several authors have utilised frame analysis in their research, inspired by Goffmann (see Goffman 1974); most notably Autesserre (2009), Barnett and Finnemore (2004), and Keck and Sikkink (1998).

${ }^{2}$ It should also be noted that despite this critical view of a conflict/resistance frame, this article uses the term 'conflict' in relation to Palestine. This is by no means meant to conceal any injustice inflicted on the Palestinian population living under Israeli occupation. Rather, the term 'conflict' is used for analytical purposes, and should be understood in a way that highlights that the Israeli occupation and settlement constructions are the prime root causes for the conflict. Adhering to the usage of the term 'conflict' stems from the article's main research interest which lies in a focus on everyday normalcy under extraordinary circumstances that are characterised by ongoing violence. In order to ensure that the associated findings are considered as relevant to other contexts - which are not related to a military occupation - I have opted for the term conflict.
} 
in conflict settings, this article will show how the attempt to pursue a normal life unfolds. Through this, everyday settings escape the magnetic effect exercised by conflicts - while feeding back into the broader political/social narrative, in particular nationalism, underpinning the front lines of this and other conflicts. As central part of these culturally scripted life projects, people develop skills to deal with changed settings and acquire a competence and new routines in order to ensure that everyday life continues in the face of crises. Despite the severe implications of conflicts, and in the present case of the Israeli occupation, everyday life is not suspended but reconfigured. Normalcy, in this sense, is about individuals' active restructuring of everyday life in the face of conflict. In order to realise the underlying culturally scripted life projects, individuals make use of techniques of 'social navigation' (Vigh 2006, 2009) which point to how they find their way to challenging social and spatial environments.

In order to illustrate empirically the role of everyday spatial practices in terms of the maintenance of normalcy in the face of conflict, this article will turn to the Palestinian notion of sumud, encompassing both a discourse as well as a diverse repertoire of everyday practices that stress a normal presence on Palestinian land. Sumud is a genuinely Palestinian concept which grew out of the Palestinian people's experience with the Israeli occupation. Both the discourse and exercise of sumud are intimately connected to Palestinian identity. In spite of this, the practice of sumud as such is not unique insofar as it represents a means to shape everyday normalcy in the face of conflict settings that can also be observed elsewhere. Accordingly, in this article sumud also serves as an illustration of the presented conceptual elaborations that stretch far beyond the case of Israel and Palestine. To provide necessary conceptual clarity, I understand everyday resistance as quotidian acts directed at the contestation of a superior power. Resilience, as understood in this article, denotes the process of adaptation to changing external circumstances (Bourbeau and Ryan 2018: 223). However, while sumud is often equated with a particular form of everyday resistance to the Israeli occupation (Johansson and Vinthagen 2015; van Teeffelen 2011; Ryan 2015), I rather present sumud as a quotidian spatial practice which is primarily aimed at achieving normalcy through pursuing 'culturally scripted life projects'. In this sense, everyday life is situated in a spatial setting in which, in the Palestinian context, the connection to both the home and the homeland play a crucial role.

The empirical insights upon which this article is based have been generated during extensive field research in Palestine. ${ }^{3}$ While practical issues of data collection necessitated an empirical focus on the West Bank and East Jerusalem, the presented observations also apply conceptually and politically/historically to the Gaza Strip. This is the case as, while Gazans live under particularly dire conditions due to the Israeli blockade, they still share the same discursive space in which sumud possesses considerable societal importance, especially when it comes to its nationalist underpinnings. The paper relies on semi-structured interviews, in-depth analyses of

\footnotetext{
3 The field work was conducted mainly during extensive stays in 2011 and 2012 but also multiple recurring shorter research stays thereafter.
} 
various documents, such as UN and NGO reports, as well as participant observation which has gained increasing prominence in the field of political science and IR in recent years. The article utilises a reiterative approach in the sense that the theoretical insights have been developed in constant dialogue with the empirical illustrations, and in turn, the latter are examined from a theory-guided perspective. First and foremost, the article intends to present a theoretical and conceptual argument which is backed up by empirical illustrations from Palestine. Therefore, this article should by no means be understood as a comprehensive case study. As a result, the presented argument claims relevance beyond Palestine. Hence, this article argues that the attempt to pursue culturally scripted life projects is a genuine feature of any conflict setting. 4

In order to develop the suggested line of argument, the article is structured in the following manner. The second section will address the limitations of a resistance focused perspective. On this basis, the third section presents the article's specific understanding of everyday normalcy in conflict settings. Subsequently, section four puts an emphasis on the spatial situatedness of everyday normalcy. Underlying everyday spatial practices will be examined further in section five, with a focus on sumud and in this relation on the two dimensions of 'maintaining a presence' and 'ensuring mobility'. These elaborations are followed by a concluding section which offers a condensed reflection of the contribution of this article to conflict analysis and everyday resistance.

\section{Limitations of a resistance-focused perspective}

Based on a critical engagement with James C. Scott's scholarship on everyday resistance, this section will identify some crucial limitations of approaches which emphasise resistance at the expense of the normalcy of the everyday. Hence, this section prepares the ground for my own understanding of everyday normalcy in conflict settings. Recent social science scholarship has witnessed a turn to the everyday (for overviews see Highmore 2002; Jacobsen 2008). This increased attention has been inspired in particular by ethnographic research for which the everyday has been a crucial context for decades. ${ }^{5}$ This greater focus on the everyday can also be observed in the case of resistance studies (see Amoore 2005; Johansson and Vinthagen 2020). In particular, James C. Scott who inspired a great deal of subsequent scholarship has emphasised that resistance not only takes place in open, declared and organised forms but as 'hidden transcripts' (Scott 1985; 1990), denoting discourses and

\footnotetext{
${ }^{4}$ Hence, while sumud as such might be a genuinely Palestinian discourse and practice, its underlying features are rather prevalent in conflict settings in general. The special issue of The Sociological Review, titled 'On other Terms', addresses the question of the uniqueness of foreign-language concepts and the potential of their translation to other contexts (Law and Mol 2020; as well as the other contributions to the special issue).

5 For an elaborate discussion about the naming of the everyday see Guillaume and Huysmans (2019).
} 
practices that occur in opposition to and are concealed from the dominant public discourse. ${ }^{6}$

Hence, according to Scott (1985: 290),

class resistance includes any act(s) by member(s) of a subordinate class that is or are intended either to mitigate or deny claims [...] made on that class by superordinate classes [...] or to advance its own claims [...] vis-à-vis those superordinate classes.

It follows from this perspective that not only collective but also individual acts constitute resistance. Moreover, this kind of conceptualisation puts the everyday at the centre of attention. Therefore, this perspective goes beyond a focus on organised, collective, open forms of resistance which have also been termed 'contentious politics' (see e.g. McAdam et al. 2001: 4-7, 2001: 4-9). As a result, there are also 'incidental' acts of resistance which are

(a) unorganized, unsystematic, and individual, (b) opportunistic and selfindulgent, (c) have no revolutionary consequences, and/or (d) imply, in their intention or meaning, an accommodation with the system of domination (Scott 1985: 292).

These everyday acts, according to Scott, represent a form of 'infrapolitics of subordinate groups' characterised by covert, informal, actions occurring in the context of everyday life (Scott 1990: 7).

While this turn towards everyday represents a substantial advancement of the study of resistance, it is problematic in several respects. First, focusing on 'hidden transcripts' runs the risk of externally ascribing qualities of resistance to everyday acts even though these were not meant as acts of resistance. As a consequence, as highlighted by Asef Bayat, 'almost any act of the subjects potentially becomes one of "resistance"" (Bayat 2010: 55). He therefore identifies an unintended essentialism in resistance studies, 'by reading too much into ordinary behaviors, interpreting them as necessarily conscious or contentious acts of defiance' (ibid.). As a result, it is difficult to distinguish quotidian acts of resistance from coping mechanisms.

Second, Scott's perspective is constricted insofar as he emphasises the importance of intentionality of the acts he observes as resistance (Scott 1985: 290-92). According to Scott, when analysing resistance, what is crucial is 'the social understanding of intention' (Scott 2020: xi, emphasis in the original). Contrary to this view, Bayat points out that ' $[\mathrm{t}]$ his intentionality, while significant in itself, obviously leaves out many types of individual and collective practices whose intended and unintended consequences do not correspond' (Bayat 2010: 53). Thus, there are acts that have not been intended as resistance - be it open or hidden - but lead to outcomes that constitute a contestation of the existing power relations. In turn, as Bayat stresses,

\footnotetext{
${ }^{6}$ While this article is primarily interested in the striving for everyday normalcy in conflict settings, a number of scholars have engaged in a critical discussion regarding the conceptualization of everyday resistance; see Hollander and Einwohner (2004), Ortner (1995), Abu-Lughod (1990), and Brown (1996).
} 
certain acts that were intended as resistance might actually result in stabilising the existing power relations.

Finally, what is crucial for the present contribution, a preoccupation with dominance and resistance may lead to the assumption that any kind of normalcy is consumed by a conflict setting. As a result, such a view runs the risk of subsuming any kind of action under a conflict/resistance frame with the result of negating the existence of any kind of normalcy in conflict settings. As I will further elaborate below, it is instead central that conflict settings lead to a transformation and adjustment of everyday normalcy as opposed to a suspension of normalcy.

Hence, while a focus on everyday resistance clearly expanded our understanding of conflict settings, there is a need not to neglect the persistence of normalcy in the face of conflict. Put more succinctly, the striving for normalcy in everyday life is a crucial feature of conflict settings in general. In contrast to a perspective preoccupied with a conflict/resistance frame, Asef Bayat's notion of the 'quiet encroachment of the ordinary' (2010: 56) takes into account the everyday in its own right. According to him, this quiet encroachment 'refers to noncollective but prolonged direct actions of dispersed individuals and families to acquire the basic necessities of their lives [...] in a quiet and unassuming illegal fashion' (Bayat 2010: 45), and to 'the silent, protracted, but pervasive advancement of the ordinary people on the propertied, powerful, or the public, in order to survive and improve their lives' (ibid.: 56). While at a first glance his perspective could be read as being consistent with Scott's understanding of everyday resistance, it is important to note that Bayat explicitly rejects an equation of the quiet encroachment of the ordinary with everyday resistance (ibid.: 51-55).

What follows from this discussion of everyday resistance for the present analysis is that an exclusive focus on a conflict/resistance frame obstructs a deeper understanding of social relations in a conflict setting. Thus, if we acknowledge that according to Foucault 'power is everywhere, but it is not everything' (Kelly 2009: 74, emphasis in the original; see also Foucault 1982), it follows that whereas the conflict undeniably represents an omnipresent background noise of social interactions, not all social relations are determined and structured by it. As the following section will show in detail, what happens, therefore, is a restructuring of everyday life in the face of conflict.

\section{Everyday normalcy in conflict settings}

This section develops the article's specific understanding of everyday normalcy in conflict settings and in this context introduces the concepts of culturally scripted life projects and social navigation. To begin with, the everyday should be less understood as a distinct level of analysis, which can be separated, for instance, from the international sphere of politics. As a result, the everyday cannot be equated with the local. Rather, it makes sense to approach the everyday from a practice-oriented perspective in the sense that it broadens the scope of what is relevant in the context of societal and political orders (see Certeau 1984; Adler and Pouliot 2011). Such a 
perspective allows for a proper consideration of mundane acts which contribute to a more comprehensive understanding of conflict dynamics.

Instead of juxtaposing the everyday and violent conflicts as opposites, it is necessary to examine how people try to maintain a sense of quotidian normalcy in the face of conflicts and study the political and social consequences of these. As a result, a conflict/resistance frame tends to exclusively structure social reality according to the binary logic of dominance/resistance instead of properly accounting for the actually existing complexity and underlying multiple nuances. In this sense, actions are often seen as being responsive to a dominant power relationship, while they should not be narrowed to mere reactions towards it. In contrast to such a resistance-focused framing, this article argues that it is of critical importance to go beyond a dichotomous observation of conflict contexts according to the logic of dominance/resistance. Thus, while the conflict represents a crucial context for the everyday lives of affected people, their actions are by no means limited to responding to oppressive power and exercising resistance. Otherwise, as Kelly rightly puts it, there would be 'a danger of over-determining violence, ignoring the mundane nature of most political conflicts' (Kelly 2008: 353). Rather, as this article argues, to a great deal, quotidian practices of people living in conflict contexts aim at maintaining a sense of normalcy in the face of extraordinary circumstances. Conflicts, from such a perspective, do not eradicate normalcy but reconfigure it. In this sense, conflicts represent the 'social condition' (Lubkemann 2008: 1) within which everyday normalcy takes place. As Lubkemann has emphasised with reference to wars in Africa, 'war has not been an "event" that suspends "normal" social processes, but has instead become the normal [...] context for the unfolding of social life' (Lubkemann 2008: 1). In other words, conflicts do not suspend normalcy. Rather, the striving for normalcy under conditions of conflict goes on, only under different circumstances (Koloma Beck 2012: 18, 2015) which also has political implications (see below).

A note of caution is warranted at this point. In this contribution, the term normalcy should not be equated with normalisation in a Foucauldian sense of a technology of power which attempts to make individuals fit to a certain societally prescribed norm (Foucault 1977: 184). At the same time, the notion of normalcy should not be confused with the anti-normalization debate in Palestinian society, namely the programmatic commitment to reject any pretence of normal vis-à-vis Israel in the face of the ongoing occupation of the Palestinian territories (Salem 2005). Rather, following Palestinian sociologist Salim Tamari, normalcy is understood here as the 'yearning for order' in everyday life in the face of conflict (Tamari 2013: 48).

In such a reading, the idea of a normalisation of a state of exception becomes fundamentally redefined in a productive sense. In this regard, it is not the case that the whole life gets subordinated under the conflict context leading to a situation in which every action is either implicitly or explicitly directed towards resistance or predetermined by an oppressive power. Instead, even in the face of conflicts, people make considerable efforts to lead a normal life. As a result, by focusing on the importance of quotidian normalcy this article revisits the relationship between everyday life and conflicts.

For this purpose, building on Lubkemann (2008), who has not provided a detailed definition of the concept, I understand culturally scripted life projects as the striving 
for normalcy in conflict settings with the aim of actively shaping this normalcy. Culturally scripted life projects possess an anchoring function as they provide individuals with an understanding for the importance of normalcy which is strong enough to resist the magnetic effect of conflicts. They are culturally scripted in the sense that individuals are confronted with certain expectations directed at their respective social roles; be it as provider for the family, ensuring its safety, or supporting children's education, or when being expected to marry. Culturally scripted life projects are, therefore, about one's place in society against the backdrop of intersubjectively shared role-expectations.

In order to realise these culturally scripted life projects, I suggest, individuals employ techniques of social navigation (Vigh 2009, 2006). The concept of social navigation helps to 'illuminate the way agents guide their lives through troublesome social and political circumstances' (Vigh 2006: 13). As I will show in detail in the next section, everyday life is fundamentally situated in a spatial context so that social navigation can be understand as a spatial practice of everyday life. ${ }^{7}$ Accordingly, social navigation often relates to detours both in a literal and figurative sense; in the exemplary case of Palestine this relates to students trying to reach Abu Dis campus of Al Quds University (see below), or parents ensuring the continuation of education in a self-organising manner after the suspension of schooling as a response to the corona virus pandemic.

\section{The space of the everyday normalcy}

Everyday experiences are always situated in a spatial environment. As Johanna Mannergren Selimovic puts it, 'the everyday is always located, and grounded, in materiality’ (Mannergren Selimovic 2019: 132). In other words, individuals organise their daily lives in a spatial setting. Hence, following Henri Lefebvre, space is socially produced through practices of everyday life, while simultaneously space affects everyday life (Lefebvre 1991). This insight also matters with regard to conflicts in general (see Björkdahl and Buckley-Zistel 2016). It is, therefore, reasonable to focus on the space of everyday life in order to make sense of how individuals attempt to maintain normalcy when being confronted with conflicts. Simply put, individuals' striving for quotidian normalcy substantially focuses on everyday spatial settings.

As will become evident, while spatial analyses in the context of Israel/Palestine have often focused on the repressive features of the Israeli occupation (Weizman 2007; Gregory 2004, 2005), in order to stress the importance of everyday normalcy and space, this article is rather interested in how Palestinians productively employ spatial practices in order to pursue their daily life (see Harker 2009; Hammami 2005, 2010; Tawil-Souri 2009, 2010).

The home plays a particular role with respect to the everyday (Mac Ginty 2019: 240-43). As David Shim has rightly pointed out: 'The home arguably functions as

\footnotetext{
7 In this sense, social navigation clearly bears resemblance with Bayat's 'quiet encroachment of the ordinary'.
} 
one of the main venues wherein most of the ordinary, repetitive, and routine activities of daily life take place. While home, thus, becomes an integral part of the everyday, the latter in turn becomes inextricably linked to (imaginaries of) place' (Shim 2016: 600). Home is therefore a crucial site where normalcy is produced. Accordingly, this article suggests also taking into account home when focusing on everyday normalcy in conflict settings.

In particular in the Palestinian case, home can be perceived as 'trans-scalar imagination', spanning from the individual home to the nation (Shim 2016: 601). As a result, everyday actions of Palestinians transcend the spatial context of their quotidian environment and acquire a meaning that affects discourses about nationalist liberation. Hence, home represents both a lived space as well as a spatial imaginary (Blunt and Dowling 2006: 142). In this context, home is also trans-scalar insofar as it transcends a clear-cut distinction between public and private, or, as Brickell puts it, between 'the public sphere of geopolitics on the one hand, and the so-called "private sphere" of everyday life on the other' (2012: 575). Consequently, homes 'may simultaneously signify the nation, the neighbourhood or just one's street' (ibid.: 575).

That the private becomes political is evident in Palestine, where the home receives attention in particular in the context of its looming destruction. This is the case in two main respects. On the one hand, the Israeli government restricts building permissions for Palestinians in East Jerusalem as well as in Area $\mathrm{C}$ of the West Bank. As a result, Palestinians build without Israeli permits leading to Israeli authorities issuing demolition orders and often also demolishing these homes (Braverman 2007; see below). On the other hand, especially during the second intifada (20002005) but also in response to violent escalations from 2015 onwards, Israel has demolished homes of Palestinians who perpetrated terror attacks as a punitive measure which is directed against the entire family of the assailant (UN OCHA 2015). Moreover, in Palestinian refugee camps, the idea of the homeland is kept alive in various ways. Most clearly, it is symbolised through the old keys of the homes the refugees had to abandon and which, in the meantime, have mostly been destroyed (see Bowker 2003: 4). These examples show that home, too, cannot escape being mainly addressed on the basis of a conflict/resistance frame. Contrary to such a perspective, however, Christopher Harker highlights that 'focusing on the destruction of Palestinian houses and homes is insufficient on its own because it persists with the familiar tendency to script Palestinian geographies primarily through the lens of the Israeli Occupation' (2009: 321, see 329).

\section{Everyday spatial practices in Palestine}

\section{Reconsidering sumud as a spatial practice}

When it comes to the topic of Palestinian everyday resistance, sumud receives a great deal of both scholarly and political attention. As sumud possesses a distinct quotidian character it is particularly useful in order to illustrate the importance of the attempt to lead a normal life in the face of a conflict setting. As Salim Tamari 
puts it, '[t]he quest for normalcy - as negation of violence and yearning for order in daily life - has become a defining theme in the politics of the quotidian in the Palestinian-Israeli conflict' (2013: 48).

Among Palestinians, in particular since the Israeli occupation of the territories of the West Bank, Gaza Strip and East Jerusalem in 1967, sumud - Arabic for steadfastness - has gained considerable prominence as a 'socio-political ideology' (Shwaikh 2020: 8). From the viewpoint of Palestinian lawyer and writer Raja Shehadeh sumud represents an alternative to either armed struggle or surrender (Shehadeh 1982; Farsoun and Landis 1990: 28). According to Qumsiyeh, sumud 'conjures up many images that reflect steadfastness, persistence and success in the face of difficult obstacles. It is not mere passive patience in the face of adversity, but rather an active form of popular resistance' (Qumsiyeh 2006: 11). In general, sumud possesses a collective dimension as a societal, often nationalist, discourse on the one hand and an individual dimension as a practice exercised by individual Palestinians on the other.

Historically, sumud as discourse and practice has undergone an important transformation in two respects. On the one hand, it is possible to identify an evolution of sumud from an unconscious tactic of survival to a deliberate strategy, forming an important element of the first intifada. This also led to the establishment of formalised institutions such as a 'sumud fund' in 1978, designated to support and control collective sumud activities, by financing activities in the context of education, agriculture, health and housing (Lindholm Schulz 1999: 55; see also Khalili 2009: 101; Dana 2015). This institutionalisation promoted nepotism in relation to sumud, thereby corrupting its original spirit (Tamari 1991: 62-63). Later, in an attempt to benefit from its positive connotation, the Palestinian Authority integrated the sumud narrative into its developmentalist agenda (Richter-Devroe 2018: 104). This could be most clearly observed when PA Prime Minister Salam Fayyad associated his institution-building program with sumud by stressing that strengthened Palestinian institutions enable individuals to continue exercising sumud (Bronner 2010; Rijke and van Teeffelen 2014: 89).

On the other hand, while originally being steadfast primarily meant a passive reaction towards the occupation, it has transformed to a form of pro-active agency which is directed at a continuation of daily life and its established routines. Hence, as Richter-Devroe (2011: 39-40) and Junka-Aikio (2016) point out, during the first intifada sumud related to the suspension of everyday normalcy, which often included substantial social pressure directed at individuals to abide by this demand (RichterDevroe 2018: 103). Contrary, since the second intifada sumud is increasingly connected to the 'affirmation of life and pleasure' (Junka-Aikio 2016: 64). This observation seems especially relevant for the Gaza Strip. At least since the Israeli blockade of the Gaza Strip which started in 2007, the Palestinian population in the Gaza Strip is confronted with a substantially different situation compared to the West Bank. In particular, while the essence of sumud is a refusal of being uprooted, people in the Gaza Strip do not have the option of leaving. Hence, as there is no alternative to staying, the exercise of sumud takes different shapes. As, for instance, Junka-Aikio shows in her study of everyday life in the Gaza Strip, Gazans appropriate the space 
of the beach as a zone of everyday leisure thereby making a deliberate display of normalcy in particularly dire circumstances (Junka-Aikio 2016: 61-64). ${ }^{8}$

Contrary to research which over-emphasises the importance of resistance for sumud, I suggest to put the underlying striving for normalcy in the face of conflict at the centre of attention. In this way, it is also possible to avoid problematic romanticisations of sumud (see Abu-Lughod 1990) which, as Susan Abulhawa put it, 'propose an otherworldly ability to withstand what no human should be forced to withstand, and they obscure the very human and very dark reality of life in Gaza' (Abulhawa 2019). As a result, such romanticisation which transforms 'an ordinary population into mythical creatures' (Baker 2016) has dehumanising implications for Palestinians who live under Israeli occupation (Shwaikh 2020: 19).

Contrary to such a view, I argue that sumud represents a distinctive spatial practice of everyday life under occupation. This focus on attempting to lead a normal life under the difficulties of a conflict cannot be underestimated. As Doumani points out, 'in Nablus, like elsewhere in the occupied Palestinian territories, there is a desperate search for normalcy' (2004: 44). Hence, regardless of whether certain everyday actions can or cannot be described as resistance, by framing them as sumud Palestinians equip their actions with a higher meaning that transcends their immediate quotidian context, also providing a sense of identity. Accordingly, framing one's everyday actions as sumud helps endure the hardships of life under occupation. In this context, sumud becomes less an act of resistance but rather a culturally scripted life project in the face of a conflict setting. Such culturally scripted life projects are for instance marriage, raising children, or pursuing an education despite the hardships of the occupation.

At the same time, sumud could also be regarded as an expression of resilience insofar as 'Palestinians work to normalise daily life under occupation, either through trying to adapt to changing circumstances, or through reproducing Palestinian identity and culture in a way that asserts the normality of a Palestinian presence on the land' (Ryan 2015: 308). Such a view resonates with a focus on resilience in both IR (e.g. Bourbeau and Ryan 2018) and has gained prominence also in practical development cooperation contexts. In Palestine, for instance, the Palestinian Authority and the United Nations Development Programme (UNDP) co-hosted the Palestine Resilience Conference 2016, subtitled 'From sumud to transformative resilience' (UNDP 2016), thereby at least implicitly equating sumud and resilience. Such a focus on resilience and its equation with sumud, however, appears problematic, as on the one hand resilience is preoccupied with adaptation to external circumstances that are

\footnotetext{
${ }^{8}$ It needs to be emphasised that even though there is a great deal of studies on the Gaza Strip, most of them either focus on humanitarian or security-related matters (Assali 2021). As a result, especially in comparison to the abundance of related scholarship on the West Bank, there is a striking absence of ethnographic studies about Gaza and Gazans (with the exception of Feldman 2008, 2009 and Junka-Aikio 2016). As Sara Roy, author of some key studies on the Gaza Strip (esp. Roy 1995), put it: 'The focus of my work has been on the Gaza Strip, an area consistently neglected by both Western and Arab scholars, particularly before the start of the Middle East peace process, and an area that remains painfully mischaracterized and misunderstood despite its political centrality' (Roy 2007: 1). Hence, Gaza somewhat remains what Ann M. Lesch already in 1985 called 'the forgotten corner of Palestine' (Lesch 1985).
} 
perceived/described as unchangeable (see Shwaikh 2020: 18). In this regard, Palestinians are often portrayed as if they possess "supernatural "coping mechanisms", (Shwaikh 2021). On the other hand, the concept of resilience risks neglecting Palestinian peculiarities as its inherent invididualism glosses over the importance of community support which is very prevalent in Palestine (Nguyen-Gillham et al. 2008: 292). As a result, it can be argued that 'the promotion of the resilience agenda is a continuation of a colonial mindset that has been so destructive in that it encourages Palestinian acquiescence rather than agitation for change' (Keelan and Browne 2020: 2). Simply put, while resilience means passive adaptation, sumud implies an active confrontation with the circumstances caused by the occupation. As the focus of this contribution lies on the reconfiguration of everyday normalcy in the face of conflict, I refrain from explicitly labelling sumud as either resistance or resilience. Such an elevation of the underlying everyday acts rather represents an ascription of a higher meaning to these mundane acts, which are, though, mainly directed at pursuing culturally scripted life projects, regardless of whether their effects might be interpreted in some ways as a contestation of the occupation.

When approaching sumud less as a way of resistance but rather as an everyday spatial practice it is still crucial to address its political implications. In other words, emphasising the quotidian qualities of sumud and refraining from its romanticisation does not mean emptying it of any political meaning. Sumud is unquestionably a political discourse and practice, as it only makes sense in the context of the Israeli occupation.

From this perspective, the site of the home plays an important role. This is the case as even if the main aim is to establish a sense of everyday normalcy, Palestinians can resort to the frame of portraying their actions as supporting the nationalist cause of resisting the occupation. The act of not giving up one's home in order to continue one's everyday life thereby becomes an expression of not giving up the Palestinian homeland as such. The individual home of a Palestinian family thereby clearly possesses a trans-scalar quality and also symbolises the home of the Palestinian nation. In this sense, pursuing everyday normalcy connects the home with the homeland in what Jean-Klein described as a process of 'self-nationalization', denoting a 'process wherein ordinary persons fashion themselves into nationalized subjects, using distinctive narrative actions and embodied practices that are woven into the practice of everyday life' (2001: 84). As a result, the language of sumud gives Palestinians a means to navigate between the fragility of everyday normalcy in the context of the conflict on the one hand and equipping one's life with a political purpose on the other. In this sense, sumud represents a firmly established pattern which insulates the everyday from the conflict while at the same time providing alternative political framings for those exercising sumud. Sumud is therefore a socially shared pattern, a frame, to which multiple aspects of Palestinian social and political life can relate, be it in the context of everyday normalcy or national identity. In other words, sumud contributes to constituting an encompassing Palestinian national identity which cannot be disrupted by the Israeli occupation, no matter how severe its restrictions are. It can therefore be argued that the language of sumud can be invoked as a discursive strategy which equips everyday acts with a higher and potentially very political meaning. 
At the same time, the importance of the home also points to the role of the family for exercising sumud. Sumud, therefore, is not merely an individual act but is anchored in the everyday interactions of families. In this context, women play a particular role. As Richter-Devroe puts it, '[o]ften it is women's task to establish some form of normality, some normal life, in this abnormal situation of political occupation, daily violence and settler-colonial exploitation' (2018: 100; see Ryan 2015). The importance of the home gives evidence to the spatial dimension of sumud. This spatial dimension also sheds light on the question of whether sumud understood in the presented way contributes to the perpetuation of the status quo of the occupation. As the next two subsections on maintaining a presence and ensuring mobility will show, sumud as a spatial quotidian practice results in both the discursive and infrastructural appropriation of space. In other words, Palestinians give up their homes and their homeland neither in a physical nor in a discursive sense. Accordingly, sumud as a means of maintaining a presence, while primarily directed at realising culturally scripted life projects, challenges the status quo of the occupation rather than normalising it. In other words, while sumud is not apolitical, its political implications are secondary to the aim of establishing everyday normalcy.

It is crucial therefore, that these everyday acts are primarily about the striving for normalcy and the pursuance of culturally scripted life projects, regardless of any nationalist references. Sumud, therefore, can be seen as the attempt to escape the magnetic effect of the conflict, by continuing with everyday life. Omar Yousef, professor of architecture at Al Quds University Jerusalem, also emphasises that the aim to ensure normalcy in everyday life is crucial: 'Even though the result of these practices may be resistance, the aim is fulfilling everyday needs' (personal interview with Omar Yousef, Professor of Architecture, Al Quds University, Jerusalem, 3 October, 2012). As a result, according to Yousef, sumud can be considered as 'an adaptation to the difficult situation in order to avoid uprooting and eviction' (Yousef 2009: 269).

As a result, there is the need to 'move [...] beyond the strict vocabulary of survival and resistance' (Bulle 2009: 27). This insight is also captured by Nasser Abourahme in his analysis of Israeli checkpoints when he observes that 'people are using the different constitutive nodes of the present [...] to reproduce their lives in ways that do not correspond to anything we might recognise as resistance or anything we can reduce to survivalism' (2011: 455; see Harker 2011). In a similar way, when asked if he sees any kind of resistance in Jerusalem towards Israeli building restrictions, Rami Nasrallah, founder of the International Peace and Cooperation Center in Jerusalem, states that what is crucial is the realisation of daily needs. According to Nasrallah, Palestinians 'are more focusing on their daily needs other than on the macro level of politics.' Instead of exercising resistance, he clarifies, 'people want to survive, want to prevent displacement. You can call it whatever you want. But in the end it is the individual selfish need of having a roof to live and preserve the right as a legal resident of Jerusalem' (personal interview with Rami Nasrallah, Director of the International Peace and Cooperation Center, Jerusalem, 21 November, 2011).

Therefore, contrary to Junka-Aikio, everyday acts in the face of the Israeli occupation should be regarded as a 'meaningful aspect of the Palestinian struggle' (2006: 
422; see Kroll-Zeldin 2018; Abu-Zahra and Kay 2012: 175-79) only insofar as they represent an attempt to lead a normal life. One can even go a step further and stress that the main objective of most Palestinians is not fighting the occupation but exactly the striving for normalcy: 'Instead of direct political participation, most Palestinians were concerned with attempts to live what passed for "ordinary lives" (Kelly 2008: 358). In this regard, Lisa Taraki stresses that a great deal of the existing writings

share a common shortcoming in that they do not render Palestinian lives very approachable or accessible. [...] The internal dynamics, stresses, and contradictions of the social groups and communities within which people live out their lives, or the sensibilities and subjectivities of individuals as they negotiate their mundane existence away from the barricades have not received much serious attention [...] (Taraki 2006: xi).

Accordingly, sumud should primarily be regarded as the attempt to actively adapt to a conflictive situation, trying to go on with everyday life under occupation, or as a way of 'getting by' (Allen 2008; see Peteet 2017: 172) while at the same time trying to equip these everyday acts with a political meaning. Accordingly, from such a point of view, adaptation should not be equated with submission or acquiescence. To the contrary, '[s]taying in one's home is an active decision rather than a passive one, and invoking the language of sumud when staying in one's home reflects adaptation to changing circumstances and external forces' (Ryan 2015: 306; see also Khalili 2009).

In both discourse and practice of sumud, two main recurrent features can be identified; first, its everydayness, and, second, its reference to Palestinian space. It is for these two reasons that sumud serves as a useful illustration for the argument that it is reasonable to overcome a conflict- and resistance-centred perspective and instead assess everyday actions in terms of their striving for normalcy in the face of conflict settings.

Concerning its spatial dimension, sumud is essentially integrated into the daily lives of those Palestinians exercising it, and it is often related to ideational or material references to the Palestinian homeland in general or the place of the own home in particular (see Peteet 2000). The importance of home is emphasised by van Teeffelen, as he points to the dire circumstances of living under occupation: "[W]hen the home itself becomes a place of oppression, even a prison, staying does become a choice - an extraordinary choice to preserve an ordinary life' (2011: 51). Moreover, the underlying two-pronged character of sumud is highlighted by van Teeffelen and Giacaman, according to whom sumud is characterised by two main elements: 'On the one hand, preserving deep roots in the homeland; on the other, stubbornly going on with life and keeping hope for the future despite all the adversities that are faced, including occupation, discrimination, expulsion, and international negligence' (van Teeffelen and Giacaman 2007: 20). Raja Shehadeh clearly captures the spatial reference of sumud as meaning 'to stay put, to cling to our homes and land by all means available' (1982: vii). Sumud, therefore, highlights the strong connection to the Palestinian homeland and the intention to maintain a presence in it. In other words, sumud 'indicated that uprootedness was not absolute; the Palestinians were still there, on the land' (Lindholm Schulz 1999: 55, emphasis in the original). 
Concerning the everydayness of sumud, Schioccet observes a 'sacralization and ritualization of the quotidian' which contributes to Palestinian identity formation, both on an individual and collective level (2011: 13). In this regard, Richter-Devroe portrays sumud as 'the steadfast and stubborn insistence on carrying on with life and even seizing every opportunity to enjoy it, despite all odds' (2011: 33, emphasis added). Moreover, the fact that telling stories of steadfastness in the face of the Israeli occupation is a crucial element of sumud, illustrates that the two dimensions of discourse and practice of sumud are closely interrelated and mutually reinforcing. Documenting everyday stories of sumud as personal diaries or individual accounts has developed as a particular form of narration (see e.g. Shehadeh 1982; Pearlman 2004). The achievement of Wendy Pearlman's book Occupied Voices, in this context, lies in amplifying Palestinian voices, which would otherwise remain unheard, thus letting 'Palestinians speak for themselves' (2004: XXVII).

To sum up, as the subsequent sections will illustrate, sumud should mainly be understood as an everyday spatial practice through which Palestinians attempt to maintain normalcy and which at the same time equips them with a sense of meaning in the face of dire circumstances. As such, therefore, sumud is less an act of resistance but rather an attempt to pursue spatially related culturally scripted life projects in response to the Israeli occupation. On this basis, I will subsume the related spatial practices under two main headings. Accordingly, one way of pursuing culturally scripted life projects relates to maintaining a spatial presence under occupation, while a second category refers to attempts of ensuring mobility. These two categories have been chosen on the one hand due to their rootedness in quotidian space. On the other hand, related threats of evictions in the case of maintaining a presence and restrictions of movement in the case of ensuring mobility belong to the key experiences of Palestinians living under Israeli occupation.

\section{Maintaining a presence}

One way of pursuing culturally scripted life projects for Palestinians is by maintaining a spatial presence in the face of the occupation. Due to the centrality of space in the discourse and practice of sumud, as manifested in references to the Palestinian homeland as well as the individual home, this section and the subsequent one will address specific spatial practices in order to illustrate the underlying striving for normalcy.

The importance of building without permits in Palestinian East Jerusalem as an expression of the attempt to maintain a spatial presence under occupation needs to be situated in a wider political context. ${ }^{9}$ During the June war of 1967 Israel conquered and subsequently formally annexed East Jerusalem, extending Israeli legislation to this part of the city (see Dumper 2014). Since this 'reunification', it is a central part of Israeli government policies to maintain the unity and indivisibility of Jerusalem, in particular by maintaining a clear Jewish majority in the city. Recent

\footnotetext{
${ }^{9}$ Similar restrictions to building apply to Area C of the West Bank, which is under full control of the Israeli armed forces.
} 
municipal plans refer to a 'demographic balance' of 60 to 40 (Margalit 2014: 102-4; Chiodelli 2017: 8-14). As an important element of maintaining this demographic ratio, Israeli authorities considerably restrict Palestinian opportunities to obtain building permits. ${ }^{10}$

Besides a lack of available land for building - only 13\% of East Jerusalem is available for Palestinian construction - considerable difficulties exist in order to obtain building permits (personal interview with Efrat Cohen-Bar, East Jerusalem Coordinator/Urbanism Planner, BIMKOM - Planners for Planning Rights, Jerusalem, 24 November, 2011). ${ }^{11}$ In order to get a permit, several requirements have to be fulfilled: First, Palestinians are required to prove land ownership which is often not recognised by Israeli authorities. Second, building is only permitted in residential areas. Third, paying license fees often is a problem for Palestinians due to a lack of sufficient financial resources. Finally, the designated land can only be used for building if it is already connected to public infrastructure (personal interview with Meir Margalit, former Jerusalem municipal council member for Meretz, Co-founder of the Israeli Committee Against House Demolitions (ICAHD), Jerusalem, 28 October, 2011). Therefore, Meir Margalit concludes that "planning in Jerusalem is a tool of control. This system is so complicated that it is almost impossible to get a building permit' (ibid.). This position is confirmed by urban planning expert Rami Nasrallah (personal interview with Rami Nasrallah, Director of the International Peace and Cooperation Center, Jerusalem, 21 November, 2011).

In response to these restrictions, in order to realise their culturally scripted life projects and continue leading a normal life under occupation, Palestinians have resorted to building in East Jerusalem without a permit from Israeli authorities. This has resulted in a situation where, according to the United Nations, at least $32 \%$ and up to $48 \%$ of the Palestinian houses in East Jerusalem have been built without permits so that more than 85,000 and up to 130,000 Palestinians in East Jerusalem live in houses which are illegal according to Israeli law (UN OCHA 2011: 36). Many of these houses are affected by a demolition order meaning that Israeli authorities are entitled to destroy them at short notice. ${ }^{12}$ According to Margalit, in 2010 there were 10,500-11,500 pending demolition orders for building structures in East Jerusalem (Margalit 2014: 32-34). Between 2000 and 2010 Israeli authorities carried out around 100 demolitions per year. As a consequence, even though Palestinians are aware that building without permit may lead to the demolition of their homes,

\footnotetext{
${ }^{10}$ Israeli authorities make use of a variety of other methods in order to maintain this demographic dominance, such as unilaterally determining the municipal boundaries of Jerusalem, manifesting these boundaries by building the separation barrier, settlement construction, withdrawal of residence permits (for an overview: UN OCHA 2011), or the discriminatory allocation of municipal funds. Concerning the latter, Margalit calculated that, for example in 2003, the Israeli municipality allocated between 8.5 and $11.75 \%$ of its budget to Palestinians in Jerusalem who constitute around 33\% of the population (Margalit 2006: 106-11).

11 See also UN OCHA (2011: 29).

12 Harker (2009) points out that framing the destruction of Palestinian property as house demolitions instead of home demolitions has important implications regarding how these acts and those affected by them are perceived.
} 
they still decide to do so in order to be able to pursue their culturally scripted life projects.

Building without a permit, therefore, represents individual acts which primarily aim at maintaining a spatial presence in Jerusalem in order to fulfil daily needs and enable participation in social life. Thereby, for example, families can send their children to schools and have access to the health care system and labour market in Jerusalem.

While building without permit should not be elevated to an act of resistance, it should also not be relegated to an act of survivalism which is grounded in desperation. Accordingly, refraining from using the label of resistance does not mean that the described acts represent a passive acquiescence to the occupation. Quite the contrary, the attempts to lead a normal life under occupation are clear expressions of active individual agency. Thus, it is crucial to emphasise that the described acts clearly go beyond mere survival (see Yousef 2009: 145-46; Braverman 2007). Reconfiguring everyday normalcy, in this context, means adjusting to the changing circumstances caused by the occupation and reconstructing one's everyday life accordingly.

\section{Ensuring mobility}

Related to building without permit in order to maintain a presence in Jerusalem is the attempt to ensure mobility in the face of Israeli restrictions to the freedom of movement of Palestinians (see Peteet 2017; Baumann 2016). In order to ensure this mobility Palestinians resort to different tactics. Most simply, enduring the often humiliating procedures at checkpoints means ensuring mobility and by no means an acquiescence of the occupation. As Peteet puts it, in this context: 'Adjustment, accommodation, and subterfuge are means of trying to pursue as normal a routine as possible under trying circumstances' (Peteet 2017: 175). In order to capture the attempt of ensuring mobility in the face of the occupation, the concept of 'social navigation' appears useful (Vigh 2006, 2009). It accounts for the fact that 'we constantly have to attune our action and trajectory to the movement of the environment we move through' (Vigh 2006: 14). Thereby, the concept of social navigation emphasises the particular challenges of movement in situations that are exposed to constant change (Vigh 2009: 420).

Due to the changing nature of these closure obstacles - of which the United Nations counted over 700 in July 2018 - the occupation represents an unpredictable, changing environment which requires social navigation in order to move and concomitantly in order to be able to realise culturally scripted life projects (UN OCHA 2018). Two very tangible illustrations of social navigation can be observed in relation to the Israeli closure policy (see Peteet 2017: 1). To avoid waiting in line for hours on their way from Ramallah to Jerusalem, or vice versa, Palestinians have set up a Facebook group in which people passing through the Qalandiya checkpoint can post an update regarding the current waiting time, sometimes illustrated by photos. As of September 2021, the group had over 64,500 members. If a long waiting time is foreseeable, Palestinians may wait for a later time to cross, or resort to different 
checkpoints - such as DCO or Hizme, depending on their ID status - in order to save time (Kuttab 2015).

Moreover, in 2019 Palestinian software developers created the smart phone app 'Doroob Navigator' which is designed to help Palestinian drivers navigate through the restrictions of movement posed by the occupation. For instance, the app helps avoiding traffic jams at checkpoints and circumvents Israeli settlements to which Palestinian cars have no access (Ayyub 2019). These two examples also correspond to Rema Hammami's observations of Qalandiya checkpoint. She highlights that in response to the impediments caused by the occupation, Palestinians aim at 'reconstructing these circuits [of social and economic relations]' (2005: 18) aiming at the continuation of everyday life.

Accordingly, as these examples have shown, a crucial means of ensuring mobility relates to circumventing the checkpoint by means of using detours (Tawil-Souri 2009: 225). In the words of Palestinian architect Omar Yousef, 'people can still slip through these gaps of power' (personal interview with Omar Yousef, Professor of Architecture, Al Quds University, Jerusalem, 3 October, 2012). Yousef describes these quotidian attempts to evade Israeli control in detail:

Between the inception of the permanent checkpoints in 1993 and the completion of certain sections of the Wall around Jerusalem in 2004, Jerusalem remained accessible through several cracks in this architecture of separation and surveillance. It was inconvenient but possible, and people 'illegally' skirted dirt roads, sneaked though fences and climbed concrete blocks in order to go to work, reach schools and hospitals, or visit family members. On Fridays, groups of people could be seen seeping through holes in the separation system, heading towards the Al-Aqsa Mosque on foot for the Friday prayers. (Yousef 2009: 124-25)

Accordingly, even after the completion of most parts of the separation barrier, some hidden paths have remained through which Palestinians from the West Bank can enter Jerusalem. For example, according to Yousef, some people stay in Jerusalem in order to work for a couple of weeks after having gained permission to enter the city for the Friday prayer or for medical treatment (personal interview with Omar Yousef, Professor of Architecture, Al Quds University, Jerusalem, 3 October, 2012).

Moreover, commuting represents another spatial practice which requires social navigation in order to circumvent the separation barrier as part of the daily route to work or university. The separation barrier, for instance, separates the Palestinian Northern suburbs of Al Ram, Bir Nabala and Dahiyat Al Bareed from the city centre of Jerusalem. Accordingly, while Palestinians with a West Bank ID are prevented from entering Jerusalem, also Palestinians with a Jerusalem ID who live on the West Bank side of the barrier are confronted with substantial difficulties in order to reach their work place, school or university since they have to accept significant detours. As a result, the way from Al Ram to the old city of Jerusalem which originally took 15 minutes now requires 45 minutes (UN OCHA 2011: 77; see also Owais 2007) By taking on the ways in spite of these difficulties, however, Palestinians continue pursuing their culturally scripted life projects on an everyday basis through the exercise of social navigation. 
Social navigation also means adapting to the occupation in other ways. Certain checkpoints which are primarily operated for Israeli settlers do not control every single car in order to avoid delays for the settlers on their daily commutes between their settlement homes in the West Bank and their workplaces in Israel proper. Instead, the personnel operating these 'settler checkpoints' carry out ethnic profiling trying to identify suspicious passengers who look Palestinian (personal interview with Omar Yousef, Professor of Architecture, Al Quds University, Jerusalem, 3 October, 2012). This constellation allows Palestinians to evade Israeli control as a Palestinian student from Birzeit University confirms:

Sometimes we want to go out in Jerusalem with a friend who only has a West Bank ID. We go from Birzeit through Hizme-Checkpoint. We have a car with a yellow Israeli license plate. I always sit beside the driver as I do not really look like a Palestinian. We turn up English music really loud. The soldiers let us pass. They might think we are settlers. It always works. [...] I have a Jerusalem ID but I live in Birzeit to study there. When I go to my parents over the week-end I use the Hizme-Checkpoint as the Israelis do not keep track of my movement there. I also go to the doctor in Jerusalem. So all in all I can still prove my existence in Jerusalem (personal interview with Palestinian Student from Birzeit University, Ramallah, 29 September, 2012).

To sum up, in order to realise everyday normalcy under occupation, ensuring mobility is of great importance. In the face of the constantly changing obstacles posed by the occupation, Palestinians make use of social navigation in order to pursue culturally scripted life projects.

\section{Conclusion}

Based on a critical engagement with the research on everyday resistance, this article aimed at problematising the juxtaposition of violent conflicts and everyday normalcy as irreconcilable opposites. Hence, instead of negating the existence of normalcy in conflict settings and concomitantly subsuming any action under a conflict/ resistance frame, this contribution has highlighted that the striving for normalcy in everyday life is a crucial feature of conflict settings in general. Accordingly, this longing for normalcy needs to be taken into account in its own right. Hence, war and conflict should not be seen as the opposite to normalcy; rather, conflicts lead to a reconfiguration of this everyday normalcy. Only by such a focus on everyday normalcy in conflict settings, we can avoid the risk of relegating any kind of everyday actions to responses towards conflicts. Instead, such a perspective allows for a more nuanced understanding of everyday life in conflict settings which accounts for those quotidian practices that mainly aim at maintaining a sense of normalcy under extraordinary circumstances.

As this article pointed out, in order to actively shape everyday normalcy in conflict settings, individuals pursue culturally scripted life projects, such as sending one's children to school or having access to healthcare. They are cultural insofar as individuals try to fulfil certain role expectations in the pursuance of 
their everyday lives. As was shown, in order to put culturally scripted life projects into practice, techniques of social navigation play a key role. These techniques possess a distinctively spatial dimension that resonates with the fact that everyday life is always spatially situated.

Note, however, that the importance of striving for normalcy in conflict settings does not mean a normalisation of, as in the present case, the occupation. Rather, while the exceptional circumstance of the occupation represents a determining feature of everyday life, what matters is that, in order to pursue culturally scripted life projects, the conflict setting constantly needs to be taken into account. This conflict settings, however, does not lead to a suspension of everyday life but to its reconfiguration.

In order to substantiate this conceptual argument empirically, this article offered a thorough reconsideration of the Palestinian notion of sumud. By stressing the problematic implications of a romanticisation of sumud, this article offered an alternative reading of sumud as a multi-faceted quotidian and strongly spatially anchored practice which is directed at leading a normal life under Israeli occupation. As a result, with this focus on the everydayness and its importance in shaping everyday normalcy, acts of sumud can be understood as attempts to realise culturally scripted life projects rather than as acts of resistance. The emphasis of sumud as the attempt of staying put on the homeland and its focus on the home gives evidence to its spatial situatedness. Hence, in order to show how Palestinians living under occupation pursue culturally scripted life projects, this article focused on the two categories of maintaining a presence and ensuring mobility which are both rooted in a quotidian spatial setting. In both contexts, it became evident that Palestinians employ techniques of social navigation in order to realise their culturally scripted life projects. Moreover, beyond the specific case of Palestine, the engagement with sumud should also be understood as a contribution to a more refined understanding of everyday normalcy in conflict settings in general.

As a result, this contribution had the dual objective of raising awareness of the importance of conceptually capturing the importance of everyday normalcy in conflict settings on the one hand. On the other hand, this article also tried to offer a reconceptualisation of sumud less as a practice and discourse of resistance but instead as a specific means of striving for quotidian normalcy under Israeli occupation - but as a firmly established frame also as a building block of an evolving political notion of Palestinian nationalism and national identity. In this sense, sumud plays an important role in navigating the complex relationship between individual normalcy and social and political purpose. Sumud, therefore, insulates everyday life from the conflict while simultaneously providing alternative political framings for those engaged in the practice of sumud. Finally, while the case of sumud has its unique features, this contribution should clearly be seen as an encouragement to pay greater attention to the role of everyday normalcy in conflicts in general. Such a view clearly appears beneficial in order to acquire a deepened understanding of conflict dynamics and the way they play out in quotidian contexts. 
Acknowledgements I am grateful to Stephan Stetter, Teresa Koloma Beck, Endre Dànyi, Susanne Fischer, Ruth Hanau-Santini, and the anonymous reviewers as well as the editors for their helpful comments on the manuscript.

\section{References}

Abourahme, Nasser (2011) 'Spatial Collisions and Discordant Temporalities: Everyday Life between Camp and Checkpoint', International Journal of Urban and Regional Research 35(2): 453-61.

Abu-Lughod, Lila (1990) 'The Romance of Resistance: Tracing Transformations of Power Through Bedouin Women', American Ethnologist 17(1): 41-55.

Abu-Zahra, Nadia and Adah Kay (2012) Unfree in Palestine: Registration, Documentation and Movement Restriction, London: Pluto Press.

Abulhawa, Susan (2019) 'How the left also dehumanises Palestinians in Gaza', Al Jazeera, available at https://www.aljazeera.com/opinions/2019/4/13/how-the-left-also-dehumanises-palestinians-ingaza (last accessed on 12 February, 2022).

Adler, Emanuel and Vincent Pouliot, eds (2011) International Practices, Cambridge and New York: Cambridge University Press.

Allen, Lori (2008) 'Getting by the Occupation: How Violence Became Normal During the Second Palestinian Intifada', Cultural Anthropology 23(3): 453-87.

Amoore, Louise, ed. (2005): The Global Resistance Reader, London: Routledge.

Assali, Hadeel (2021) 'Hyper-Present Absence: Suggested Methods', in Michael Sorkin and Deen Sharp, eds, Open Gaza: Architectures of Hope, 326-37, New York: American University in Cairo Press.

Autesserre, Séverine (2009) 'Hobbes and the Congo: Frames, Local Violence, and International Intervention', International Organization 63(2): 249-80.

Ayyub, Rami 'Palestinian App Helps Drivers Avoid Israeli Checkpoint Bottlenecks', Reuters, 8 August.

Baker, Rana (2016) 'On the sumoud narrative and its dangers', Middle East Monitor, available at https:// www.middleeastmonitor.com/20160618-on-the-sumoud-narrative-and-its-dangers/ (last accessed on 12 February, 2022).

Barnett, Michael and Martha Finnemore (2004) Rules for the World: International Organizations in Global Politics, Ithaca: Cornell University Press.

Baumann, Hanna (2016) 'Enclaves, Borders, and Everyday Movements: Palestinian Marginal Mobility in East Jerusalem', Cities 59: 173-82.

Bayat, Asef (2010) Life as Politics: How Ordinary People Change the Middle East, Stanford: Stanford University Press.

Björkdahl, Annika and Susanne Buckley-Zistel, eds (2016) Spatialising Peace and Conflict: Mapping the Production of Places, Sites and Scales of Violence, Houndmills, Basingstoke, Hampshire: Palgrave Macmillan.

Blunt, Alyson and Robyn Dowling (2006) Home, London: Routledge.

Bourbeau, Philippe and Caitlin Ryan (2018) 'Resilience, Resistance, Infrapolitics and Enmeshment', European Journal of International Relations 24(1): 221-39.

Bowker, Robert (2003) Palestinian Refugees: Mythology, Identity and the Search for Peace, Boulder: Lynne Rienner.

Braverman, Irus (2007) 'Powers of Illegality: House Demolitions and Resistance in East Jerusalem', Law \& Social Inquiry 32(2): 333-72.

Brickell, Katherine (2012) 'Geopolitics of Home', Geography Compass 6(10): 575-88.

Bronner, Ethan (2010) 'Palestinians Try a Less Violent Path to Resistance', New York Times, available at https://www.nytimes.com/2010/04/07/world/middleeast/07westbank.html (last accessed on 12 February, 2022).

Brown, Michael F. (1996) 'On Resisting Resistance', American Anthropologist 98(4): 729-35.

Bulle, Sylvaine (2009) "'We Only Want to Live”: From Israeli Domination Towards Palestinian Decency in Shu'fat and Other Confined Jerusalem Neighborhoods', Jerusalem Quarterly (38): 24-34.

Busse, Jan (2018) Deconstructing the Dynamics of World-Societal Order: The Power of Governmentality in Palestine, London: Routledge.

Certeau, Michel de (1984) Practice of Everyday Life, Berkeley and Los Angeles: University of California Press. 
Chiodelli, Francesco (2017) Shaping Jerusalem: Spatial Planning, Politics and the Conflict, New York: Routledge.

Dana, Tariq (2015). 'Corruption in Palestine: A Self-Enforcing System', Al Shabaka Policy Brief, available at https://al-shabaka.org/briefs/corruption-in-palestine/ (last accessed on 12 February, 2022).

Doumani, Beshara (2004) 'Scenes from Daily Life: The View from Nablus', Journal of Palestine Studies 34(1): 37-50.

Dumper, Michael (2014) Jerusalem Unbound, New York: Columbia University Press.

Feldman, Ilana (2008) Governing Gaza: Bureaucracy, Authority, and the Work of Rule, 1917-1967, Durham: Duke University Press.

Feldman, Ilana (2009) 'Gaza's Humanitarianism Problem', Journal of Palestine Studies 38(3): 22-37.

Farsoun, Samih K. and Jean M. Landis (1990) 'The Sociology of an Uprising: The Roots of the Intifada', in Jamal R. Nassar and Roger Heacock, eds, Intifada: Palestine at the Crossroads, 15-35, New York: Praeger.

Foucault, Michel (1977) Discipline and Punish: The Birth of the Prison, New York: Vintage Books.

Foucault, Michel (1982) 'The Subject and Power', Critical Inquiry 8(4): 777-95.

Goffman, Erving (1974) Frame Analysis: An Essay on the Organization of Experience, Boston: Northeastern University Press.

Gregory, Derek (2004) 'Palestine and the "War on Terror"', Comparative Studies of South Asia, Africa and the Middle East 24(1): 183-95.

Gregory, Derek (2005) 'Splintering Palestine', in Henk van Houtum, Oliver Thomas Kramsch, and Wolfgang Zierhofer, eds, B/ordering Space, 123-37, Aldershot: Ashgate.

Guillaume, Xavier and Jef Huysmans (2019) 'The Concept of "the Everyday": Ephemeral Politics and the Abundance of Life', Cooperation and Conflict 54(2): 278-96.

Hammami, Rema (2005) 'On the Importance of Thugs: The Moral Economy of a Checkpoint', Jerusalem Quarterly (22-23): 16-28.

Hammami, Rema (2010) 'Qalandiya: Jerusalem's Tora Bora and the Frontiers of Global Inequality', Jerusalem Quarterly (41): 29-51.

Harker, Christopher (2009) 'Spacing Palestine Through the Home', Transactions of the Institute of British Geographers 34(3): 320-32.

Harker, Christopher (2011) 'Geopolitics and Family in Palestine', Geoforum 42(3): 306-15.

Highmore, Ben, ed. (2002) The Everyday Life Reader, London ; New York: Routledge.

Hollander, Jocelyn A. and Rachel L. Einwohner (2004) 'Conceptualizing Resistance', Sociological Forum 19(4): 533-54.

Jacobsen, Michael Hviid, ed. (2008) Encountering the Everyday: An Introduction to the Sociologies of the Unnoticed, Houndmills, Basingstoke, Hampshire: Palgrave.

Jean-Klein, Iris (2001) 'Nationalism and Resistance: The Two Faces of Everyday Activism in Palestine During the Intifada', Cultural Anthropology 16(1): 83-126.

Johansson, Anna and Stellan Vinthagen (2015) 'Dimensions of Everyday Resistance: The Palestinian Sumūd', Journal of Political Power 8(1): 109-39.

Johansson, Anna and Stellan Vinthagen (2020): Conceptualizing 'Everyday Resistance': A Transdisciplinary Approach, London: Routledge.

Junka, Laura (2006) 'The Politics of Gaza Beach: At the Edge of the Two Intifadas', Third Text 20(34): 417-28.

Junka-Aikio, Laura (2016) Late Modern Palestine: The Subject and Representation of the Second Intifada, New York: Routledge.

Keck, Margaret E. and Kathryn Sikkink (1998) Activists Beyond Borders: Advocacy Networks in International Politics, Ithaca: Cornell University Press.

Keelan, Emma Patricia and Brendan Ciarán Browne (2020) 'Problematising Resilience: Development Practice and the Case of Palestine', Development in Practice 30(4): 459-71.

Kelly, Mark G. E. (2009) The Political Philosophy of Michel Foucault, New York: Routledge.

Kelly, Tobias (2008) 'The Attractions of Accountancy: Living an Ordinary Life During the Second Palestinian Intifada', Ethnography 9(3): 351-76.

Khalili, Laleh (2009) Heroes and Martyrs of Palestine: The Politics of National Commemoration, Cambridge: Cambridge University Press.

Koloma Beck, Teresa (2012) The Normality of Civil War: Armed Groups and Everyday Life in Angola, Frankfurt: Campus Verlag. 
Koloma Beck, Teresa (2015) 'Jenseits des Ausnahmezustands' [Beyond the State of Emergency], in Stephan Lessenich, ed., Routinen der Krise - Krise der Routinen, Verhandlungen des 37. Kongresses der Deutschen Gesellschaft für Soziologie in Trier 2014, 30-39.

Kroll-Zeldin, Oren (2018) 'Institutionalized Separation and Sumud in Jerusalem's Periphery - Survival and Resistance in Shaykh Sa'd', Jerusalem Quarterly (73): 101-16.

Kuttab, Daoud (2015) 'Facebook group shares checkpoint wait in real time', Al-Monitor, available at https://www.al-monitor.com/originals/2015/04/paletine-gaza-facebook-checkpoint-israeli-traffichizma.html (last accessed on 12 February, 2022).

Law, John and Annemarie Mol (2020) 'Words to think with: An introduction', Sociological Review 68(2): 263-82.

Lefebvre, Henri (1991) The Production of Space, Oxford: Blackwell.

Lesch, Ann M. (1985) 'Gaza: Forgotten Corner of Palestine', Journal of Palestine Studies 15(1): 43-61.

Lindholm Schulz, Helena (1999) The Reconstruction of Palestinian Nationalism: Between Revolution and Statehood, Manchester: Manchester University Press.

Lubkemann, Stephen C. (2008) Culture in Chaos: An Anthropology of the Social Condition in War, Chicago: University of Chicago Press.

Mac Ginty, Roger (2019) 'Circuits, the Everyday and International Relations: Connecting the Home to the International and Transnational', Cooperation and Conflict 54(2): 234-53.

Mannergren Selimovic, Johanna (2019) 'Everyday Agency and Transformation: Place, Body and Story in the Divided City', Cooperation and Conflict 54(2): 131-48.

Margalit, Meir (2006) Discrimination in the Heart of the Holy City, Jerusalem: International Peace and Cooperation Center.

Margalit, Meir (2014) Demolishing Peace: House Demolitions in East Jerusalem, Jerusalem: International Peace and Cooperation Center.

McAdam, Doug, Sidney Tarrow, and Charles Tilly (2001) Dynamics of Contention, Cambridge: Cambridge University Press.

Nguyen-Gillham, Viet, Rita Giacaman, Ghada Naser, and Will Boyce (2008) 'Normalising the Abnormal: Palestinian Youth and the Contradictions of Resilience in Protracted Conflict', Health \& Social Care in the Community 16(3): 291-98.

Ortner, Sherry B. (1995) 'Resistance and the Problem of Ethnographic Refusal', Comparative Studies in Society and History 37(1): 173-93.

Owais, Abdalla (2007) 'The Wall and the Enclaves: Case Studies in Disrupted Communities', in Robert D. Brooks, ed., The Wall: Fragmenting the Palestinian Fabric in Jerusalem, 77-136, Jerusalem: International Peace and Cooperation Center.

Pearlman, Wendy (2004) Occupied Voices: Stories of Everyday Life from the Second Intifada, New York: Nation Books.

Peteet, Julie (2000) 'Refugees, Resistance and Identity', in John A. Guidry, Michael D. Kennedy, and Mayer N. Zald, eds, Globalizations and Social Movements: Culture, Power, and the Transnational Public Sphere, 183-209, Ann Arbor: University of Michigan Press.

Peteet, Julie (2017) Space and Mobility in Palestine, Bloomington: Indiana University Press.

Qumsiyeh, Mazin B. (2006) Popular Resistance in Palestine: A History of Hope and Empowerment, London: Pluto Press.

Richter-Devroe, Sophie (2011) 'Palestinian Women's Everyday Resistance: Between Normality and Normalisation', Journal of International Women's Studies 12(2): 32-46.

Richter-Devroe, Sophie (2018) Women's Political Activism in Palestine: Peacebuilding, Resistance, and Survival, Urbana: University of Illinois Press.

Rijke, Alexandra and Toine van Teeffelen (2014) 'To Exist Is To Resist: Sumud, Heroism, and the Everyday', Jerusalem Quarterly (59): 86-99.

Roy, Sara (1995) The Gaza Strip: The Political Economy of De-Development, Washington: Institute for Palestine Studies.

Roy, Sara (2007) Failing Peace: Gaza and the Palestinian-Israeli Conflict, London: Pluto Press.

Ryan, Caitlin (2015) 'Everyday Resilience as Resistance: Palestinian Women Practicing Sumud', International Political Sociology 9(4): 299-315.

Salem, Walid (2005) 'The Anti-Normalization Discourse in the Context of Israeli-Palestinian PeaceBuilding', Palestine-Israel Journal 12(1), available at https://pij.org/articles/334/the-antinormal ization-discourse-in-the-context-of-israelipalestinian-peacebuilding(last accessed on 12 February, 2022). 
Schiocchet, Leonardo (2011). 'Palestinian Sumud: Steadfastness, Ritual and Time Among Palestinian Refugees', Birzeit University Working Paper, available at https://dx.doi.org/10.2139/ssrn.2130405 (last accessed on 12 February, 2022).

Scott, James C. (1985) Weapons of the Weak: Everyday Forms of Peasant Resistance, New Haven: Yale University Press.

Scott, James C. (1990) Domination and the Arts of Resistance: Hidden Transcripts, New Haven: Yale University Press.

Scott, James C. (2020) 'Foreword', in Anna Johansson and Stellan Vinthagen, Conceptualizing 'Everyday Resistance': A Transdisciplinary Approach, ix-xi, London: Routledge.

Shehadeh, Raja (1982) The Third Way: A Journal of Life on the West Bank, London: Quartet Books.

Shim, David (2016) 'Between the International and the Everyday: Geopolitics and Imaginaries of Home', International Studies Review 18(4): 597-613.

Shwaikh, Malaka (2020) 'Engendering hunger strikes: Palestinian women in Israeli prisons', British Journal of Middle Eastern Studies 0(0): 1-19.

Shwaikh, Malaka (2021) 'The Dehumanizing Discourse of Resilience', Progressive Policy Review, 28/05/2021, available at https://ppr.hkspublications.org/2021/05/28/resilience-discourse/ (last accessed on 12 February, 2022).

Tamari, Salim (1991) 'The Palestinian Movement in Transition: Historical Reversals and the Uprising', Journal of Palestine Studies 20(2): 57-70.

Tamari, Salim (2013) 'Normalcy and Violence: The Yearning for the Ordinary in Discourse of the Palestinian-Israeli Conflict', Journal of Palestine Studies 42(4): 48-60.

Taraki, Lisa (2006) in Lisa Taraki, ed., Living Palestine: Family Survival, Resistance, and Mobility under Occupation, xi-xxx, Syracuse: Syracuse University Press.

Tawil-Souri, Helga (2009) 'New Palestinian Centers: An Ethnography of the "checkpoint Economy", International Journal of Cultural Studies 12(3): 217-35.

Tawil-Souri, Helga (2010) 'Qalandia Checkpoint: The Historical Geography of a Non-Place', Jerusalem Quarterly (42): 26-48.

UNDP (United Nations Development Programme) (2016) 'Palestine Resilience Conference 2016: From Sumud to Transformative Resilience', 24-25 November 2016, Amman, Jordan, available at https:// www1.undp.org/content/dam/papp/docs/Publications/UNDP-papp-research-PRC_Building\%20Res ilience\%20in\%20Gaza.pdf (last accessed on 30 December 2021).

UN OCHA (United Nations Office for the Coordination of Humanitarian Affairs) (2011) East Jerusalem: Key Humanitarian Concerns. Special Focus, March 2011, available at http://www.ochaopt.org/ documents/ocha_opt_jerusalem_report_2011_03_23_full_english.pdf (last accessed on 30 December 2021).

UN OCHA (2015) The Monthly Humanitarian Bulletin, November 2015, available at https://www.ochao pt.org/content/punitive-house-demolitions-resume (last accessed on 30 December 2021).

UN OCHA (2018) The Monthly Humanitarian Bulletin, September 2018, available at: https://www.ochao pt.org/sites/default/files/hummonitor_september_2018.pdf (last accessed on 30 December 2021).

van Teeffelen, Toine (2011) Sumud: Soul of the Palestinian People, Bethlehem: Arab Educational Institute.

van Teeffelen, Toine and Fuad Giacaman (2007) 'Resistance in Daily Life', in Toine van Teeffelen, ed., Challenging the Wall: Toward a Pedagogy of Hope, 20-29, Bethlehem: Arab Educational Institute.

Vigh, Henrik (2009) 'Motion Squared: A Second Look at the Concept of Social Navigation', Anthropological Theory 9(4): 419-38.

Vigh, Henrik E. (2006) Navigating Terrains of War: Youth and Soldiering in Guinea-Bissau, New York: Berghahn Books.

Weizman, Eyal (2007) Hollow Land: Israel's Architecture of Occupation, London: Verso.

Yousef, Omar M. (2009) Urban Morphologies of Conflict: Palestinian life and Israeli planning in Jerusalem, PhD Dissertation, University of California, Irvine.

\section{List of Interviews}

Personal interview with Omar Yousef, Professor of Architecture, Al Quds University, Jerusalem, 3 October, 2012. 
Personal interview with Rami Nasrallah, Director of the International Peace and Cooperation Center, Jerusalem, 21 November, 2011.

Personal interview with Efrat Cohen-Bar, East Jerusalem Coordinator/Urbanism Planner, BIMKOM Planners for Planning Rights, Jerusalem, 24 November, 2011.

Personal interview with Meir Margalit, former Jerusalem municipal council member for Meretz, Cofounder of the Israeli Committee Against House Demolitions (ICAHD), Jerusalem, 28 October, 2011.

Personal interview with Palestinian Student from Birzeit University, Ramallah, 29 September, 2012.

Publisher's Note Springer Nature remains neutral with regard to jurisdictional claims in published maps and institutional affiliations.

Jan Busse is senior research fellow and lecturer in Global Politics and Conflict Studies at the University of the Bundeswehr Munich, Germany. His research focuses on global historical sociologies of political order, the Israeli-Arab conflict, political dynamics in the Middle East and North Africa, and EU-Mediterranean Relations. In 2018, his book Deconstructing the Dynamics of World-Societal Order: The Power of Governmentality in Palestine was published by Routledge in the New International Relations Series. $\mathrm{He}$ is the editor of the volume The Globality of Governmentality: Governing an Entangled World (2021, Routledge) and co-editor of a special issue titled 'Facing the Facts on Tremulous Grounds: Analysing Political Dynamics in the Middle East and North Africa a Decade after the Arab Uprisings' (with André Bank) published in the journal Mediterranean Politics (2021). 